\title{
Surface location and orientation of the lantibiotic nisin bound to membrane-mimicking micelles of dodecylphosphocholine and of sodium dodecylsulphate
}

\author{
Henno W. VAN DEN HOOVEN, Chris A. E. M. SPRONK, Mart VAN DE KAMP, Ruud N. H. KONINGS \\ Cornelis W. HILBERS and Frank J. M. VAN DE VEN \\ NSR Center for Molecular Structure, Design and Synthesis, Laboratory of Biophysical Chemistry, \\ University of Nijmegen, Nijmegen, The Netherlands \\ (Received 26 July 1995) - EJB 95 1241/3
}

The interaction of nisin, a membrane-interacting cationic polypeptide, with membrane-mimicking micelles of zwitterionic dodecylphosphocholine and of anionic sodium dodecylsulphate was studied. Direct contacts have been established through the observation of NOEs between nisin and micelle protons. Spin-labeled DOXYL-stearic acids were incorporated into the two micellar systems. From the paramagnetic broadening effects induced in the 'H-NMR spectrum of nisin it is concluded that the molecule is localized at the surface of the micelles. The interactions of nisin with zwitterionic and with anionic micelles resemble each other as do the nisin conformations [van den Hooven, H. W., Doeland, C. C. M., van de Kamp, M., Konings, R. N. H., Hilbers, C. W. \& van de Ven, F. J. M. (1995) Eur. J. Biochem. 235, 382-393]. The hydrophobic residues are immersed into the micelles and oriented towards the center, whereas the more polar or charged residues have an outward orientation. The micellar systems are considered to model the first step in the mechanism of antimicrobial action of nisin, this step is the binding of nisin to the cytoplasmic membrane of target bacteria. Detailed information on this initial binding step is obtained. Hydrophobic and electrostatic interactions appear to be involved in the nisin-micelle contacts. It is suggested that subtilin, a lantibiotic structurally related to nisin, has a comparable membrane interaction surface.

Keywords: bacteriocin; lanthionine-containing polypeptide; mode of action; NMR; spin label.

The polycyclic 34-residue-containing polypeptide nisin (Gross and Morell, 1971) (Fig. 1) belongs to the class of lanthionine-containing polypeptides known as lantibiotics (Schnell et al., 1988). They are characterized by the occurrence of unusual amino acids, such as lanthionine, 3-methyllanthionine, dehydroalanine (Dha) and dehydrobutyrine (Dhb). Lantibiotics are the end products of ribosomal synthesis and post-translational modifications. They are produced by a large number of Grampositive bacteria; the producer of nisin is Lactococcus lactis subsp. lactis. The post-translational modification involves dehydration of serines and threonines resulting in $\alpha, \beta$-unsaturated amino acids, of which some react with thiol groups of cysteine residues to form lanthionine or 3-methyllanthionine (Ingram, 1970).

Nisin possesses bactericidal activity against a wide range of Gram-positive bacteria or their spores. Because of this activity it is exploited as a food preservative in the dairy and canning

Correspondence to C. W. Hilbers, NSR Center, Faculty of Science, Laboratory of Biophysical Chemistry, Toernooiveld, NL-6525 ED Nijmegen, The Netherlands

Fax: +31243652112 .

Abbreviations. Alas, 3-methylalanyl moiety of $(2 S, 3 S, 6 R)$-3-methyllanthionine; Alas, 1)-alanyl moiety of meso-lanthionine; $\mathrm{Ala}$, L-alanyl moicty of meso-lanthionine or of $(2 S, 3 S, 6 R)$-3-methyllanthionine; $1 / 2 /$ 3D, one-/two-/three-dimensional; Dha, dehydroalanine; Dhb, dehydrobutyrine (3-methyldehydroalanine); DodPCho, dodecylphosphocholine; $\triangle \Psi$, transmembrane potential; NOESY, NOE spectroscopy; ppb, parts per billion; ppm, parts per million; TOCSY, total correlated spectroscopy; TPPI, time-proportional phase incrementation. industry (Hurst, 1981; Delves-Broughton, 1990; Vandenbergh, 1993). The primary target of nisin is the cytoplasmic membrane, in which membrane-potential-dependent pores are formed (Ruhr and Sahl, 1985; Henning et al., 1986; Kordel and Sahl, 1986; Sahl et al., 1987; Bruno et al., 1992; Okereke and Montville, 1992; Abee et al., 1994; Winkowski et al., 1994). For intact cells the threshold potential is between $-50 \mathrm{mV}$ and $-80 \mathrm{mV}$ at pH 7.5 and below $-50 \mathrm{mV}$ at pH 5.5 (Sahl et al., 1987). In vitro studies have indicated that the activity of nisin is highly dependent on the phospholipid composition (Gao et al., 1991; García Garcerá et al., 1993; Driessen et al., 1995).

The aim of our research is to unravel the structure/function relationship of nisin. Previously, we and others have reported its structure in aqueous solution (Chan et al., 1989b; Slijper et al., 1989; van de Ven et al., 1991; Lian et al., 1992). Recently, we have reported preliminary studies in membrane-mimicking environments (van den Hooven et al., 1993). A solvent less polar than water (trifluoroethanol/water) and micelles of both the zwitterionic dodecylphosphocholine (DodPCho) and the anionic sodium dodecylsulphate (SDS) were used as model systems. In the accompanying study the three-dimensional (3D) solution structures of nisin in the micellar model systems are presented (van den Hooven et al., 1995). Despite the different polar head groups of the detergents, the spatial structures of nisin when complexed to DodPCho or to SDS micelles appear to be similar. In the first ring of nisin these structures, however, differ from that in aqueous solution. The manner in which nisin influences the membrane function is highly dependent on its orientation with respect 


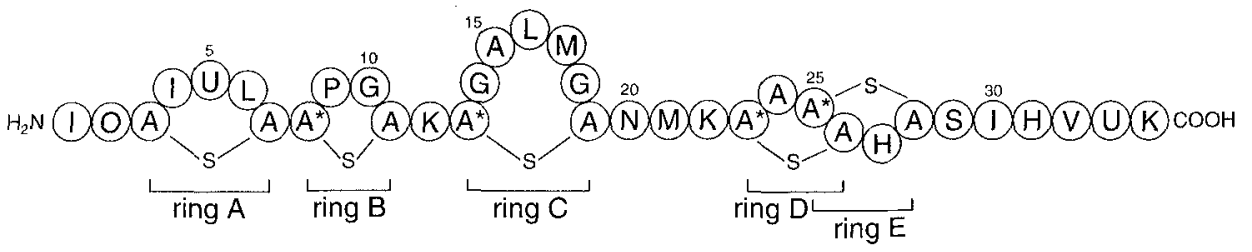<smiles>C=C(N)C(=O)O</smiles><smiles>C/C=C(/NC)C(=O)O</smiles><smiles>CC(N)C(C)CSCC(=O)O</smiles><smiles>CC(CC(C)(C)C(C)(N)C(=O)O)C(C)(N)C(=O)O</smiles>

Fig. 1. The primary structure of nisin and structures of the unusual amino acids. (a) $U$, dehydroalanine; (b) $O$, dehydrobutyrine; (c) $\hat{L}_{S} \hat{\lrcorner}$, lanthionine; and (d) $\stackrel{A}{S}_{S} \stackrel{A}{\lrcorner}, 3$-methyllanthionine.

to the membrane. Here we report that in the presence of DodPCho and of SDS micelles it is located on their surface. These observations will be used to describe a model of the in teraction between nisin and cellular membranes.

\section{MATERIALS AND METHODS}

Chemicals. Nisin was obtained as a gift of Aplin \& Barrett. Prior to its use in NMR studies it was further purified by reverse-phase HPLC (Rollema et al., 1991). $\left[{ }^{2} \mathrm{H}_{25}\right]$ SDS and $\left[{ }^{2} \mathrm{H}_{38}\right]$ Dod $P$ Cho were obtained from MSD Isotopes. [ $\left.{ }^{1} \mathrm{H}_{25}\right] \mathrm{SDS}$ was from Biorad and $\left[{ }^{\prime} \mathrm{H}_{38}\right]$ DodPCho was a kind gift of Drs R. Dijkman and H. M. Verheij (University of Utrecht). 5-DOXYL stearic and 16-DOXYL-stearic acid were purchased from Aldrich, while deuterated methanol was from Merck.

ESR spectroscopy. ESR spectra were recorded at $313 \mathrm{~K}$ on a Bruker ESP300 X-band spectrometer as described previously (Brown et al., 1981; Mendz et a1., 1988, 1991). The pH of the micellar samples was 3.5 ( $\mathrm{pH}$ meter reading).

${ }^{13}$ C-NMR spectroscopy of SDS and DodPCho. Sample conditions were essentially as previously described (Brown et al., 1981). ${ }^{13} \mathrm{C}-\mathrm{NMR}$ spectra were measured at $100.62 \mathrm{MHz}$ on a Bruker AM 400 spectrometer, interfaced to an Aspect 3000 computer. Standard composite-pulse proton decoupling was used. The experiments were conducted at $313 \mathrm{~K}$. The number of datapoints was $32 \mathrm{k}(1 \mathrm{k}=1024)$, the number of scans 512 and the sweep width $25 \mathrm{ppm}$ or $55 \mathrm{ppm}$ for SDS and DodPCho, respectively. The spectral region of $25 \mathrm{ppm}$ for SDS was such that the resonance of the $\mathrm{CH}_{2}$ group next to the sulphate moiety of SDS was folded back in the spectrum. The data were processed using NMR1 softwarc (New Methods Research, Inc., Syracuse, NY). No window function was used and the data were zerofilled to $64 \mathrm{k}$. The line width of the ${ }^{13} \mathrm{C}$ resonances was determined by curve fitting.

${ }^{1}$ H-NMR spectroscopy of nisin/micelle complexes with spin-labels. Samples for the experiments with spin-labels were prepared by first dissolving nisin in $0.5 \mathrm{ml} \mathrm{H}_{2} \mathrm{O} /{ }^{2} \mathrm{H}_{2} \mathrm{O}(9: 1)$ or in ${ }^{2} \mathrm{H}_{2} \mathrm{O}$ to a concentration of $3 \mathrm{mM}$ and then adding $\left[{ }^{2} \mathrm{H}\right] \mathrm{SDS}$ to a concentration of $100 \mathrm{mM}$ or $\left[{ }^{2} \mathrm{H}\right] \mathrm{Dod} P \mathrm{Ch}$ to a concentration between $100 \mathrm{mM}$ and $120 \mathrm{mM}$, resulting in a 30-40-fold excess of detergent. The $\mathrm{pH}$ was adjusted to 3.5 ( $\mathrm{pH}$ meter reading). A small aliquot $(1-2 \mu l)$ of spin-labeled stearic acid, taken from $0.1 \mathrm{M}$ stock solutions in deuterated methanol, was then added.
Spin-label titrations at 298 and $313 \mathrm{~K}$ were performed with DOXYL-stearic acid concentrations in the range $0.1-0.6 \mathrm{mM}$ to determine the optimum amount for large and specific effects.

'H-NMR experiments were performed at $400 \mathrm{MHz}$ on a Bruker AM400 spectrometer, interfaced to an Aspect 3000 computer. Two different types of 1D NMR spectra were recorded: (a) with a simple $\pi / 2$ pulse preceded by water irradiation, or (b) with a $\pi / 2$ pulse followed by a $25-\mathrm{ms}$ spin-lock period as in a total correlated spectroscopy (TOCSY) sequence (Bax and Davis, 1985; Griesinger et al., 1988). The spin-label titrations were analyzed by subtracting the Fourier-transformed spectra recorded for samples with and without spin-label using standard Bruker software. 2D-MLEV17-TOCSY spectra (Bax and Davis, 1985; Griesinger et al., 1988) were recorded in the phase-sensitive mode using the time-proportional-phase-incrementation (TPPI) method (Redfield and Kunz, 1975; Marion and Wüthrich, 1983). The carrier was placed at the water resonance. The $\mathrm{H}_{2} \mathrm{O}$ signal was suppressed by continuous irradiation during the relaxation delay of $1.5 \mathrm{~s}$. The experiments were performed at $313 \mathrm{~K}$. The spectral width was $12 \mathrm{ppm}$ for nisin/SDS and $15 \mathrm{ppm}$ for nisin/DodPCho samples in both dimensions; the number of data points amounted to 400 -to-512 in $t_{1}$ and 2048 in $t_{2}$, the number of scans was typically 32 . The mixing times were $25 \mathrm{~ms}$ and $22 \mathrm{~ms}$ for nisin/SDS and nisin/DodPCho, respectively. 2D-MLEV17-TOCSY experiments were performed with $\mathrm{H}_{2} \mathrm{O} /{ }^{2} \mathrm{H}_{2} \mathrm{O}(9: 1)$ and ${ }^{2} \mathrm{H}_{2} \mathrm{O}$ samples. The spin-label concentrations of the samples were in the range of $0.2-0.4 \mathrm{mM}$. The data were processed on an Aspect3000 computer. A $\pi / 4$-shifted sine bell apodization was used in both dimensions. $2 \mathrm{D}$ relative-difference spectra were obtained by subtracting TOCSY spectra recorded for samples with and without spin-label, using in-housewritten software, on a Bruker Aspect3000 computer. Relative differences were obtained as $I=\left(I_{a}-f \times I_{1}\right) / I_{\mathrm{a}}$, where $I$ is the peak height in the relative difference spectrum, $I_{n}$ is the peak height in the spectrum recorded for a sample without and $l_{\mathrm{l}}$, with spin-label; $f$ is the factor used to scale the latter TOCSY spectrum. To determine $f$, rows and columns of the 2D spectra including peaks not affected by the spin-label were extracted. The optimal factor is determined using standard Bruker software by optimizing the nilling of the unaffected resonances in the difference spectrum. As noise signals can give rise to artifacts in relative difference spectra, peak heights below a chosen level were not taken into account. 
'H-NMR spectroscopy of complexes of nisin and protonated micelles. Samples contained $4 \mathrm{mM}$ nisin and a 25 -fold excess of ['H]SDS or ['H]DodPCho in $0.5 \mathrm{mI} \mathrm{H}_{2} \mathrm{O}^{2} \mathrm{H}_{2} \mathrm{O}(9: 1)$ at pH 3.5. NOESY spectra (Jeener et al., 1979; Bodenhausen et al., 1984) with a mixing time of $500 \mathrm{~ms}$ were recorded at $298 \mathrm{~K}$ and $313 \mathrm{~K}$ on a Bruker AMX600, operating at $600 \mathrm{MHz}$ and interfaced to a Bruker Aspect X32 computer. Acquisition was essentially the same as described above for the TOCSY spectra. The solvent was also irradiated during the mixing time. The number of scans was 64. Processing of the data was performed on a Bruker Aspect X32 computer. Prior to Fourier transformation a $\pi / 3$-shifted sine bell apodization was applied in both dimensions and in the $t_{1}$ direction the data were zerofilled to 1024. Baseline corrections were necessary and were performed after Fourier transformation.

\section{RESULTS AND DISCUSSION}

General remarks. The data obtained in this study are interpreted on the basis of the 3D structures of nisin when complexed to membrane-mimetic micelles of DodPCho or of SDS that are described in the accompanying report (van den Hooven et al., 1995). Two structured domains are found, a structured N-terminal domain encompassing the first three lanthionine rings A, B and $\mathrm{C}$, when nisin is bound to DodPCho, or the first two or three lanthionine rings when nisin is bound to SDS micelles. This domain is connected (via a hinge region) to a structured Cterminal domain encompassing the residues Lys 22 to ${ }_{s} \mathrm{Ala} 28$, involving three consecutive overlapping $\beta$-turns which include the two intertwined lanthionine rings $\mathrm{D}$ and $\mathrm{E}$. Although the regions flanking the two domains show structural variability, a tendency for extended structures has been observed. The molecule is amphipathic in two ways. First, the charged and hydrophilic amino acids are mainly located in the C-terminal half of the molecule, whereas the majority of the residues in the $\mathrm{N}$ terminal half is hydrophobic and only a single charged residue, Lys 12 , is present. Secondly, both of the aforementioned domains have a hydrophobic and a hydrophilic side.

\section{Miscellaneous observations suggesting a surface location of} nisin. A number of initial observations indicated that nisin is localized at the surface of DodPCho and of SDS micelles. First, the line widths of ${ }^{13} \mathrm{C}$ resonances of DodPCho and SDS near the polar head-group are (slightly) increased upon addition of nisin, whereas there is almost no effect on resonances from the micellar center. Second, amide proton exchange measured for nisin in both micellar systems, by dissolving a protonated sample in ${ }^{2} \mathrm{H}_{2} \mathrm{O}$ and following the loss of intensity of the NH proton signals, is still quite fast. After an hour only a few NH resonances can be observed. Although for most of the amide protons for which the exchange could be followed, the process is slower than was observed for nisin in aqueous solution, no part of the polypeptide is completely protected by the micelles against exchange of its amide protons, indicating that the lantibiotic is not buried in the micelle. Third, for nisin/SDS, the $\mathrm{pK}$ of of both His 27 and His 31 is 7.5 , whereas for nisin in water and nisin complexed to DodPCho micelles the $\mathrm{pK}_{u}$ of both histidines is 6.5 (van den Hooven et al., 1993). The $\mathrm{pK}_{\text {a }}$ shift observed for the nisin/SDS system can be explained by the electrostatic effect of adjacent negatively charged sulphate groups (Sachs et al., 1971), indicating that the histidine side chains reside at the micellar surface. Fourth, the line widths of proton resonances of nisin in both micellar systems are smaller than theoretically expected for a nisin/micelle complex of about $15 \mathrm{kDa}$ (van den Hooven et al., 1995), which again is indicative of additional

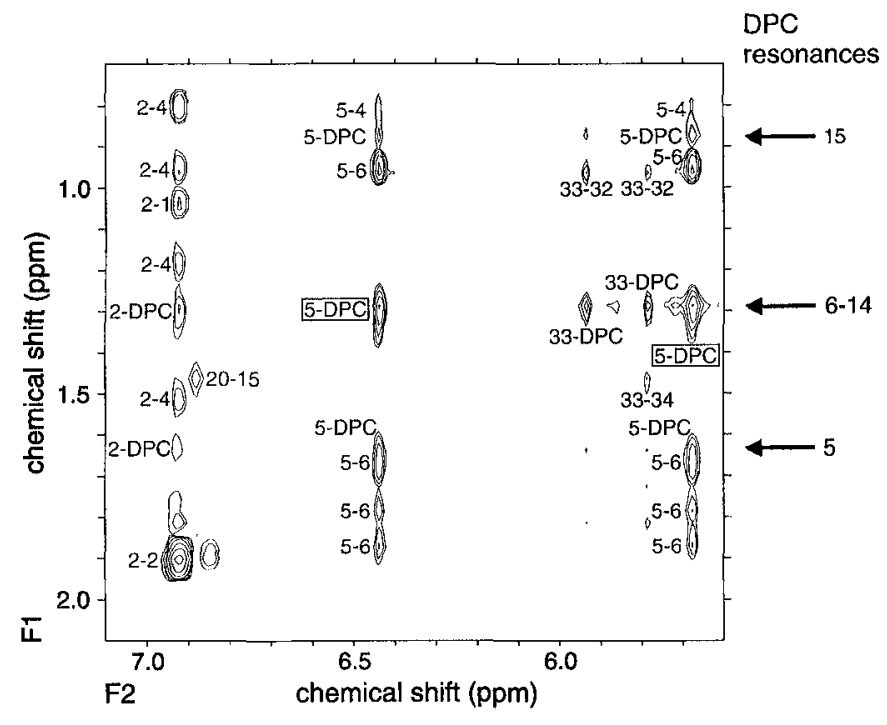

Fig. 2. Intermolecular NOEs between nisin and protonated DodPCho. Part of a $600 \mathrm{MHz}$ NOESY spectrum of nisin/DodPCho, recorded with a mixing time of $500 \mathrm{~ms}$, at $313 \mathrm{~K}$ and $\mathrm{pH} 3.5$. The numbers in the NOESY spectrum refer to residue positions in nisin. Cross-peaks can be seen from $\mathrm{H}^{\prime \beta}$ protons of the $\alpha, \beta$-unsaturated amino acids, Dhb2, Dha5 and Dha33 (along the horizontal axis) to other nisin resonances and to the ['H]DodPCho resonances $15,6-14$ and 5 (numbering along the $F 2$ axis, see Fig. 3). A comparison of NOESY spectra recorded for samples with protonated and with perdeuterated Dod $P$ Cho shows that the cross-peaks from the resonance of the $\mathrm{H}^{\beta}$ protons of Dha5 to the resonance 5 of DodPCho and to the resonance of the $\mathrm{H}^{x}$ proton of Leu6 are indeed two cross-peaks. Relatively strong NOEs between nisin and protonated DodPCho are observed for the $\mathrm{H}^{\beta}$ resonances of Dha5 and the corresponding cross-peaks are boxed.

flexibility, allowed by surface interactions of nisin with the micelles. A difference in line width has been observed for resonances of the central rigid micelle-spanning helix and of the less rigid surface-located helix of the major coat protein of bacteriophage M13 (van de Ven et al., 1993). Fifth, the observed structural variability in the NOE-derived structure of nisin in the presence of DodPCho and of SDS micelles is probably caused by flexibility (van den Hooven et al., 1995) and renders a transmicellar orientation unlikely.

Nisin-detergent NOEs indicate complexation. A possible interaction of nisin and micelles might be detectable via direct NOE contacts between nisin and protonated detergent molecules. Therefore NOESY experiments were performed at $313 \mathrm{~K}$, the temperature at which the data for the 3D-structure elucidation was obtained. To observe intermolecular NOEs it was necessary to change the nisin/detergent ratio from 1:30-40 to 1:25. Furthermore, the experiments were conducted at $600 \mathrm{MHz}$ and a long mixing time of $0.5 \mathrm{~s}$ was chosen to increase NOE intensities. A distinction between intramolecular nisin and intermolecular nisin-detergent NOEs could be made by comparing NOESY spectra in the presence of protonated and of perdeuterated micelles. Additional information was obtained from a NOESY spectrum recorded at $298 \mathrm{~K}$, where some overlap problems encountered at $313 \mathrm{~K}$ could be resolved. NOEs were observed between nisin and detergent resonances (Fig. 2) in the part of the spectrum downfield from the residual water signal, whereas this was precluded in the region upfield of the water signal due to overlap problems. The resonance positions of the ' $\mathrm{H}$ resonances of DodPCho and SDS are given in Fig. 3.

Quite a number of intermolecular NOEs were observed, which clearly demonstrate complexation between nisin and the 

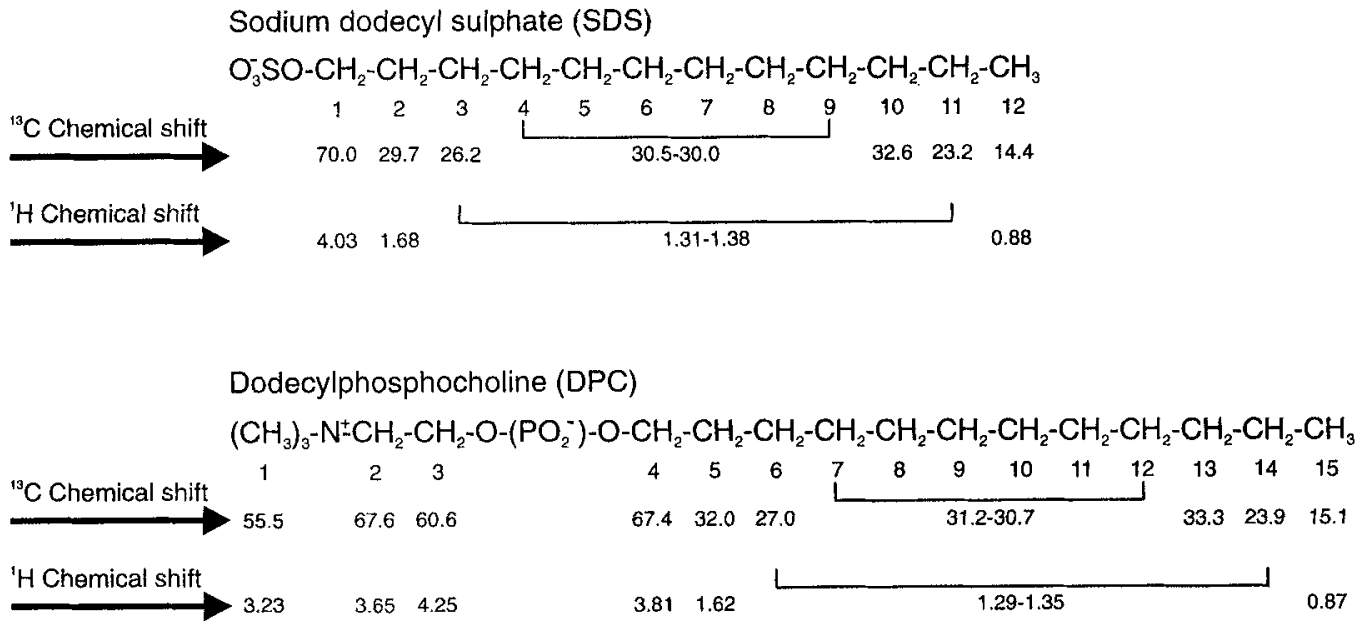

Fig. 3. Structures of the anionic sodium dodecylsulphate and the zwitterionic dodecylphosphocholine with numbering of carbon and hydrogen atoms. The ${ }^{13} \mathrm{C}-\mathrm{NMR}$ spectra of SDS and DodPCho have been partially assigned (Kragh-Hansen and Riisom, 1976; Brown et al., 1981). Based on chemical shift data, e.g. (Birdsall et al., 1972), multiplet structure and spin-decoupling experiments we assigned a few more ${ }^{13} \mathrm{C}$ resonances and the complete 'H-NMR spectrum of SDS and of DodPCho. The chemical shifts in this figure are given in ppm. Overlapping resonances are indicated by brackets.

micelles. Of the detergent resonances those overlapping at about $1.3 \mathrm{ppm}$ gave the strongest NOEs to resonances of nisin, but also cross-peaks from detergent resonances at the micellar surface to nisin resonances were observed; in two cases connectivities to the methyl group of the dodecyl chain were seen. The intensities of the nisin-detergent NOEs differ clearly. The micelles are dynamical aggregates. Individual detergent molecules can change places, can move along the diameter of the micelle and can swing up and down (Godici and Landsberger, 1974; Menger and Doll, 1984). Further, nisin is still flexible (van den Hooven et al., 1995) and its depth of immersion into the micelles may vary slightly in time. This explains, together with spin diffusion, that a number of detergent resonances give NOEs to nisin resonances, though to a different extent. As an example, in Fig. 2 it can be seen that the $\mathrm{H}^{\beta}$ protons of Dha5 give relatively strong NOEs to the overlapping resonances of DodPCho, whereas those of Dhb2 and Dha33 are weak. Although the results obtained for both systems are not completely identical because of different overlap problems, it can be concluded that the relatively strong NOEs observed are from nisin protons distributed over the whole polypeptide sequence and located at the hydrophobic sides of the two structured domains in correspondence with the results obtained in the spin-label experiments.

Spin-labeled probes incorporated in micelles. The micelle-inserted parts of nisin can be probed with intramicellar spin-labels, for which the position in the micelle must be known. We determined the incorporation of the two spin-labeled 5-DOXYL-stearic and 16-DOXYL-stearic acids in micelles of DodPCho and of SDS through observation of a broadening of the ESR lines of the nitroxide spin-labels and a decrease in the hyperfine splitting. A similar approach has been used for DodPCho micelles (Brown et al., 1981). The micelles were found to consist of $30-$ 50 detergent molecules as determined from the detergent concentration dependence of the widths of the ESR lines of the nitroxide radicals, as previously described (Brown et al., 1981). In the presence of nisin the spin-labels are incorporated into micelles, which consist of 30-50 detergent molecules (data not shown).

The paramagnetic spin-label probes induce in the NMR spectrum line broadening of the resonances of nuclei in their vicinity. This effect was used to determine the position of the spin-labels of the 5-DOXYL-stearic and 16-DOXYL-stearic acids in the micelles by recording ${ }^{13} \mathrm{C}$-NMR spectra at natural abundance. The resonance positions of the ${ }^{13} \mathrm{C}$ resonances of DodPCho and SDS are given in Fig. 3. We note that the average number of spin-labels/micelle in our samples is smaller than one, so that interactions between spin-labels can be neglected. The line broadening caused by 5-DOXYL-stearic acid was most pronounced for the detergent resonances of ${ }^{13} \mathrm{C}$ atoms located near the polar head-groups, whereas the effect of 16-DOXYL-stearic acid was the largest at the apolar end of the carbon chain (data not shown). Similar results have been obtained for other micellar systems (Brown et al., 1981; Mendz et al., 1988, 1991; Papavoine et al., 1994). These results indicate qualitatively that the nitroxide moiety of 16-DOXYL-stearic acid is most of the time near the center of the micelles, whereas the label of 5-DOXYLstearic acid is, on average, close to the surface, i.e. near the phosphate groups of DodPCho and just underneath the sulphate of SDS.

The addition of nisin does not significantly alter the effect of the spin-labels on the ${ }^{13} \mathrm{C}$ resonances of DodPCho and SDS, indicating that the relative orientation of the spin-labeled molecules within the micelles does not appreciably change. The nisin/ detergent aggregate can be regarded as a complex with a typical micellar organization. These results formed the basis for the following studies on the interaction between nisin and the spinlabeled micelles.

Spin-labels demonstrate a location and orientation of nisin at the micellar surface. Using the two different spin-labels, intramicellar and extra-micellar locations can be determined. Using the same spin-label approach the polypeptide-hormone glucagon and the bee-venom constituent melittin were found to bind to the surface of DodPCho micelles (Brown et al., 1981, 1982). Studies of the myelin basic protein indicated that this molecule is also located primarily near the surface of DodPCho and of mixed DodPCho/palmitoyl/phosphatidic acid micelles (Mendz et al., 1984, 1988, 1990, 1991). A different situation was encountered for the major coat protein of bacteriophage M13; this protein is composed of a long hydrophobic helix that traverses the SDS micelle and a shorter amphipathic helix that is situated on the surface of the micelle (Papavoine et al., 1994). In the present study the homonuclear spectra with and without 


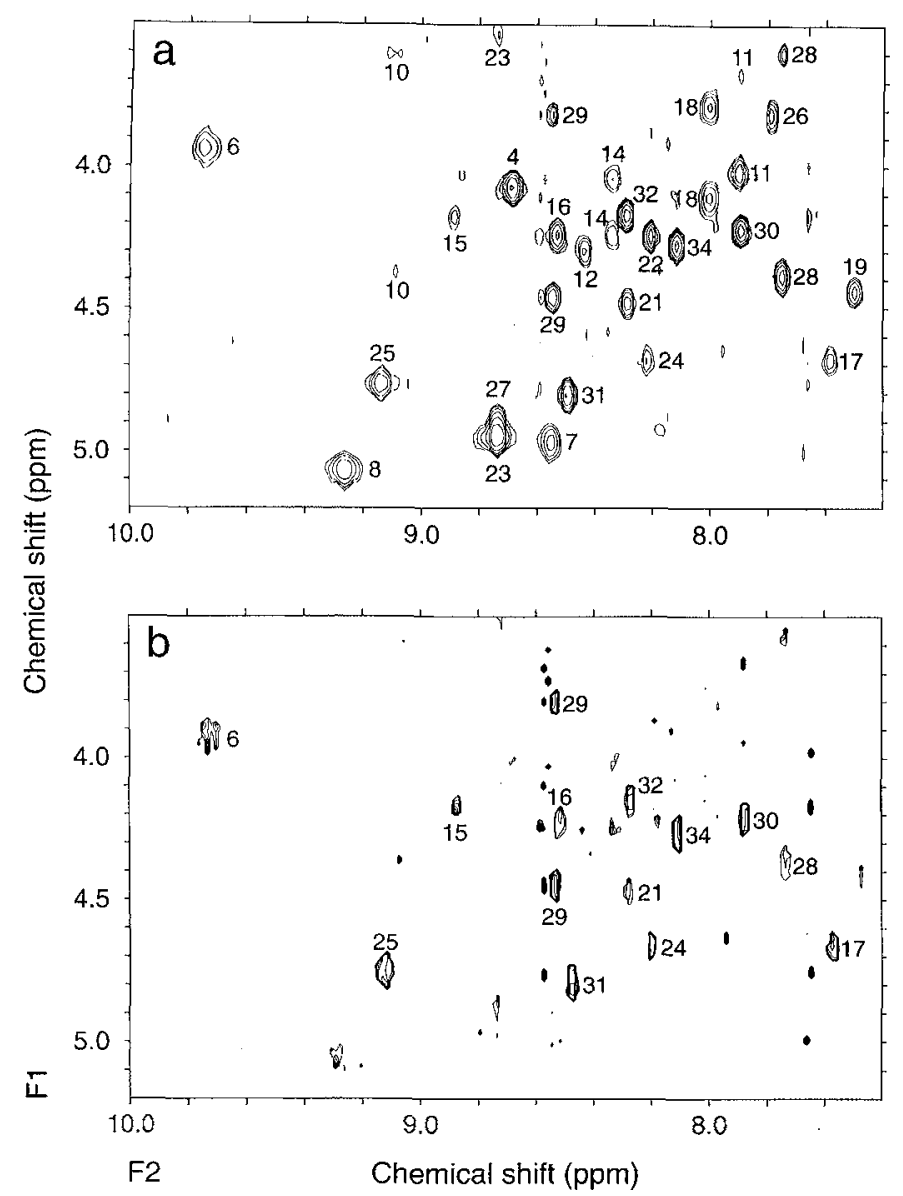

Fig. 4. Effect of the spin-labeled molecule 5-DOXYL-stearic acid on the NMR spectrum of nisin/DodPCho. (a) NH-H" region of a TOCSY spectrum of nisin/DodPCho, recorded with a mixing time of $22 \mathrm{~ms}$, at $313 \mathrm{~K}$ and $\mathrm{pH} \mathrm{3.5}$, and (b) corresponding region of the relative difference spectra with 5-DOXYL-stearic acid (sce Materials and Methods). The numbers refer to residue positions in nisin. The contouring in the relative difference spectrum starts at $30 \%$ with increments of $10 \%$. Intensities observed in the difference spectrum at the edges of the peaks in the corresponding TOCSY recorded with a sample without spin-label (e.g. for Gly14) are not interpreted as spin-label induced effects. Spurious peaks resulting from noise can be seen in the difference spectrum as intense diamond-shaped cross-peaks at positions where no nisin peaks are expected. Most of these noise-induced intensities occur in the T1noise bands at the positions of the resonances of the ring protons of His 27 and of His 31 .

spin-label were analyzed by relative-difference $2 \mathrm{D}$ spectra instead of 1D NMR, which allows for a larger number of resonances to be investigated unambiguously.

The two different spin-labels induce specific line-broadening effects in the 'H-NMR spectrum of nisin in the presence of $\operatorname{Dod} P$ Cho and of SDS. These labels do not change the chemical shifts, indicating that they have little or no effect on the conformation of nisin. A spin-label cencentration of $0.2 \mathrm{mM}$ to $0.4 \mathrm{mM}$ was found to be most appropriate for optimal, strong and specific, broadening effects in the spectrum of $3 \mathrm{mM}$ nisin samples. The line broadening was estimated from the peak height in relative-difference spectra (Fig. 4) obtained by subtracting 2D-MLEV17-TOCSY spectra recorded for samples with and without spin-label. The resonances of the $\alpha, \beta$-unsaturated amino acids did not give rise to cross-peaks in the TOCSY spectra, but were well resolved in the 1D NMR spectrum. For these resonances the spin-label-induced line broadening was
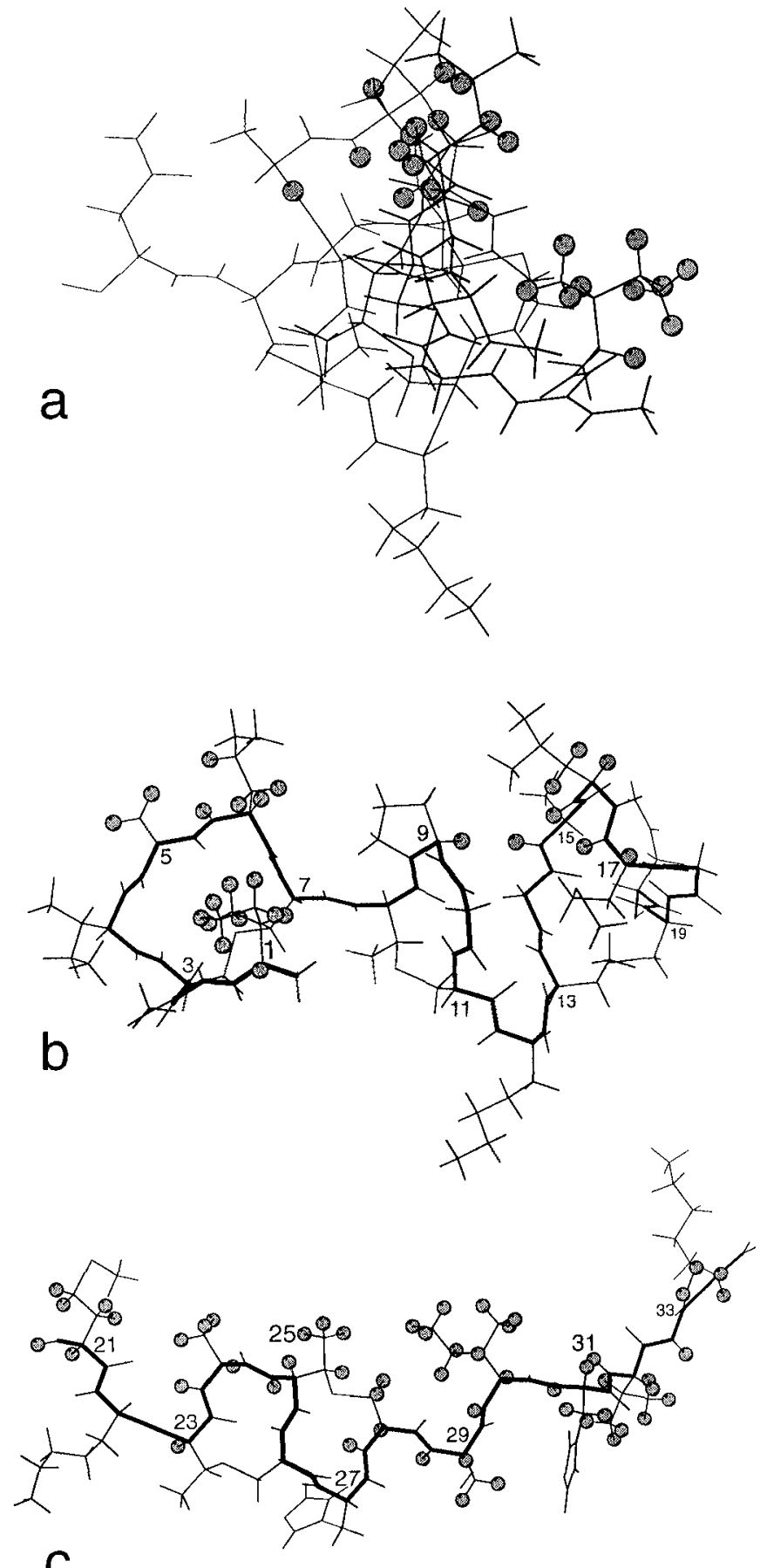

Fig. 5. Effect of spin-label on nisin. Protons of which the resonances are broadened by micelle-inserted 5-DOXYL-stearic acid are indicated by spheres in fragments of a representative structure of nisin complexed to DodPCho micelles (van den Hooven et al., 1995) of (a, b) the residues Ile1-Asn20 and of (c) Met21-Lys34. The different views on the fragment Ile $1-A \operatorname{sn} 20$ in the subligures (a) and (b) are obtained by a rotation of $90^{\circ}$. The $\mathrm{N}$-terminal and $\mathrm{C}$-terminal halves of the nisin molecule are shown from different viewpoints for optimal views on the diflerent ring systems. In the subfigures (b) and (c) the backbone is indicated by a thick line and the odd-numbered residues are labeled at their $\mathrm{C}^{\prime \prime}$ atom. The structure was drawn with the program MolScript (Kraulis, 1991).

evaluated from a $1 \mathrm{D}$ difference spectrum. In the 2D TOCSY difference spectra the influenced protons are traced back via the observed cross-peaks. If a majority of the cross-peaks, stemming from a given proton, showed up in the relative difference spectra a line broadening effect was attributed to that particular proton. 


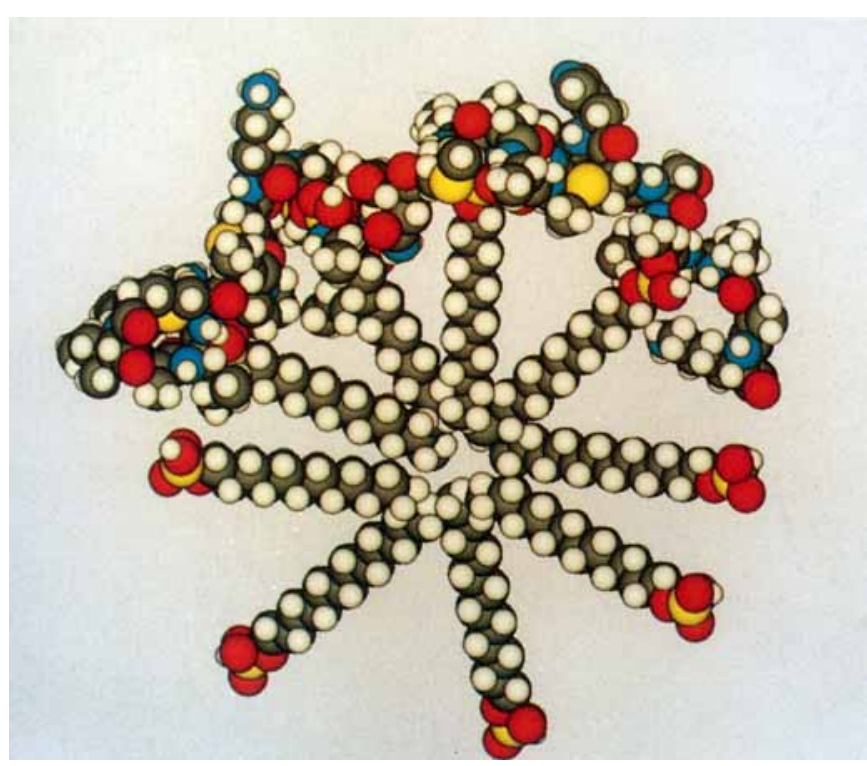

Fig. 6. Schematic representation of the interaction of nisin with a SDS micelle. Nine SDS molecules with extended conformation were placed to form a circular array to represent a micelle. One representative structure of nisin (van den Hooven et al., 1995) was positioned at the surface of the micelle. The N-terminus of nisin is at the upper left corner, whereas the $\mathrm{C}$-terminus is at the upper right corner. For the $\mathrm{N}$-terminal structured domain the side chains of Leu6 and Leu16 are the deepest immersed into the micelle, whereas the side chain of Lys 12 is protruding outwards.

The effects of both spin-labels on nisin/DodPCho and on nisin/SDS were the same. The 5-DOXYL-stearic and 16DOXYL-stearic acids essentially affect the same nisin resonances, although 5-DOXYL-stearic acid is more effective in the sense that at a given concentration for several resonances the broadening is stronger than for 16-DOXYL-stearic acid and 10$15 \%$ of the resonances affected by 5-DOXYL-stearic acid are not influenced by 16-DOXYL-stearic acid. The resonances of the following residues are broadened:, Ile1, Dha5, Leu6, Ala15, Leu16, Met17, Met21, Ala24, Ala*25 [Alas, 3-methylalanyl moiety of $(2 S, 3 S, 6 R)-3$-methyllanthionine], ${ }_{s} \mathrm{Ala} 28$ ( $\mathrm{s}$ Ala, Lalanyl moiety of meso-lanthionine or of $(2 S, 3 S, 6 R)$-methyllanthionine), Ser29, Ile30, His31, Val32, Dha33 and Lys34. For
Gly10 only a few cross-peaks with low intensity were observed in the TOCSY spectra hampering the evaluation of the data for this residue. The strongest effects, i.e. the highest extent of line broadening, are observed for the residues Ile1 and Ile30-Lys34. The protons giving rise to broadened resonances are distributed over the whole, more or less extended, molecule and are not confined to a limited region of the molecule. These and other observations (see above) are interpreted in terms of a model in which nisin is localized at the surface of both DodPCho and SDS micelles.

From the distribution of the residues which exhibit broadened resonances information about the orientation of the molecule on the surface of the micelles is obtained. The positions of the protons of which the resonances are broadened by 5 DOXYL-stearic acid are indicated (Fig. 5) in the 3D structure of nisin complexed to DodPCho micelles (van den Hooven et al., 1995). In the structured $\mathrm{N}$-terminal domain comprising the residues $\mathrm{Ala}_{\mathrm{s}} 3$ to $\mathrm{Ala} 19$ all hydrophobic residues except Ile4 are influenced by the spin-labels. The affected protons reside on one side of this amphipathic domain (Fig. 5b), meaning that the hydrophobic residues are immersed below the charged surface of the micelles. In the structured $\mathrm{C}$-terminal domain encompassing the residues Met21 to ${ }_{s} \mathrm{Ala} 28$ the amino acids Lys22, Ala* 23, sAla26 and His27 are on one side and Met21, Ala24, $\mathrm{Ala}_{\mathrm{S}}^{*} 25$ and ${ }_{S} \mathrm{Ala} 28$ on the other side. The latter are much more influenced by the spin-labels than those on the other side (Fig. 5c). This suggests that as for the N-terminal domain, the hydrophobic side of the C-terminal domain is immersed in the hydrophobic interior of the micelle, whereas the more hydrophilic side of this part of the molecule resides at the charged surface. The global picture that emerges from these observations is that nisin is localized at the surface of the micelles and oriented such that the hydrophobic residues are immersed below the surface, whereas the more polar or charged residues have an outward orientation (Fig. 6).

The results obtained from the NOESY experiments are in accord with those of the spin-label experiments, which suggests that the DOXYL-stearic acids have no major influence on the interaction between nisin and the micelles, justifying the use of these paramagnetic probes. Overlap problems are much less severe in the spin-label approach, where also the aliphatic spectral region can be utilized to derive information. This renders it much more suitable for the study of the interaction between polypeptides and micelles than the polypeptide-detergent NOEs.

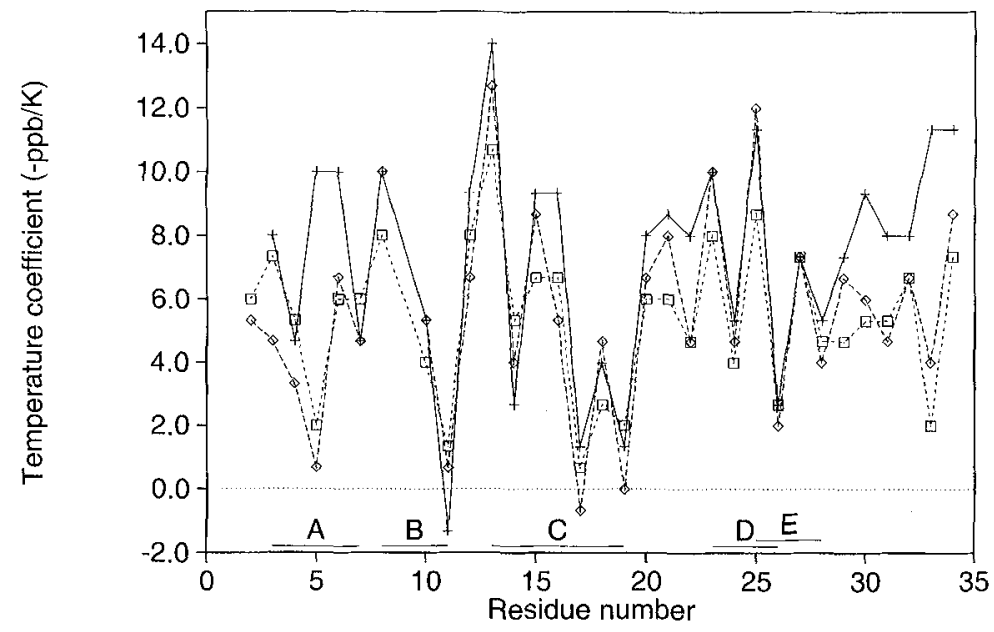

Fig. 7. Amide proton temperature coefficients. These coefficients are given in -ppb/K for nisin in aqueous solution (+), and complexed to SDS $(\square)$ and to DodPCho $(\diamond)$ micelles. The positions of the rings $A-E$ are indicated. 
Temperature coefficients as indicators of solvent shielding. Now that both the conformation (van den Hooven et al., 1995) and the location of nisin complexed to DodPCho and to SDS micelles is known, we can attempt to interpret the temperature coefficients. Amide proton temperature coefficients are indicative of hydrogen bonding and/or of shielding from the solvent. These coefficients have been calculated from the assignments at different temperatures for nisin in aqueous solution (Slijper et al., 1989) and in micellar systems (van den Hooven et al., 1993) and are shown in Fig 7. The magnitudes of the amide-proton temperature coefficients are nearly the same for nisin complexed to DodPCho and to SDS micelles. Two large differences of about $-8 \mathrm{ppb} / \mathrm{K}$ are observed between nisin in water and in the micellar systems, strikingly for both dehydroalanines. For Dha5 this can be explained by a different conformation of the flanking (trans) peptide bonds which flipped by almost $180^{\circ}$ when transferred from water to a membrane-like environment (van den Hooven et al., 1995). There are no indications that the conformation of the C-terminus, including Dha33, in water differs from that in the micellar systems, and in all three systems no hydrogen bonds were observed for the residues Ser29-Lys34. The $\mathrm{NH}$ resonances of the five consecutive residues Ile30-Lys 34 all have a reduced temperature coefficient in the micellar systems compared to nisin in aqueous solution. These coefficients are medium-range for nisin in the micellar systems and the corresponding amide protons are not the slowest exchanging $\mathrm{NH}$ protons. Our explanation of this difference in temperature coefficients is that the nisin amide protons of the residues Ile30Lys34 are in the micellar systems more shielded from the solvent than in aqueous solution, which is caused by an interaction with the micelles. This is in correspondence with the spin-label experiments, where the largest induced line-broadening effects were observed for resonances of the C-terminal residues Ser29Lys 34 , proving that this sequence is in close contact with the micelles.

Model of pore-forming activity. In current models on the mechanism of action of nisin it is assumed that it forms transient multistate pores in the cytoplasmic membrane of the target cell (Sahl, 1991; García Garcerá et al., 1993; Driessen et al., 1995). The first step in the formation of these pores is the binding of nisin to the membrane, where nisin is supposed to adopt an amphipathic conformation upon contact with the membrane, the contacts of which are primarily based on ionic forces (Sahl, 1991). The binding step is followed by aggregation and membrane-potential-dependent insertion. The order of the latter two events is not known. In the pores the nisin molecule is thought to be amphipathic and oriented with its hydrophobic side towards the membrane and with its hydrophilic side towards the water-filled channel. The amphipathicity has been demonstrated for nisin in aqueous solution (van de Ven et al., 1991) and for nisin complexed to membrane-mimetic micelles (van den Hooven et al., 1995).

Opinions differ with regard to the orientation of nisin with respect to the membrane in the binding step. It has been suggested that the charged and polar residues contact the membrane surface, while the hydrophobic side remains exposed to water (Sahl, 1991). If we take the binding to the micellar systems studied here as a model for membrane binding we prefer the opposite view with the polar residues at the surface and the hydrophobic residues immersed in the membrane.

The N-terminal half of the nisin molecule contains mainly hydrophobic residues, the most hydrophobic ones are immersed in the micelles. For this half of the molecule hydrophobic interactions are likely to dominate the nisin-micelle contacts. The C-terminal half is much more hydrophilic and again the hy-
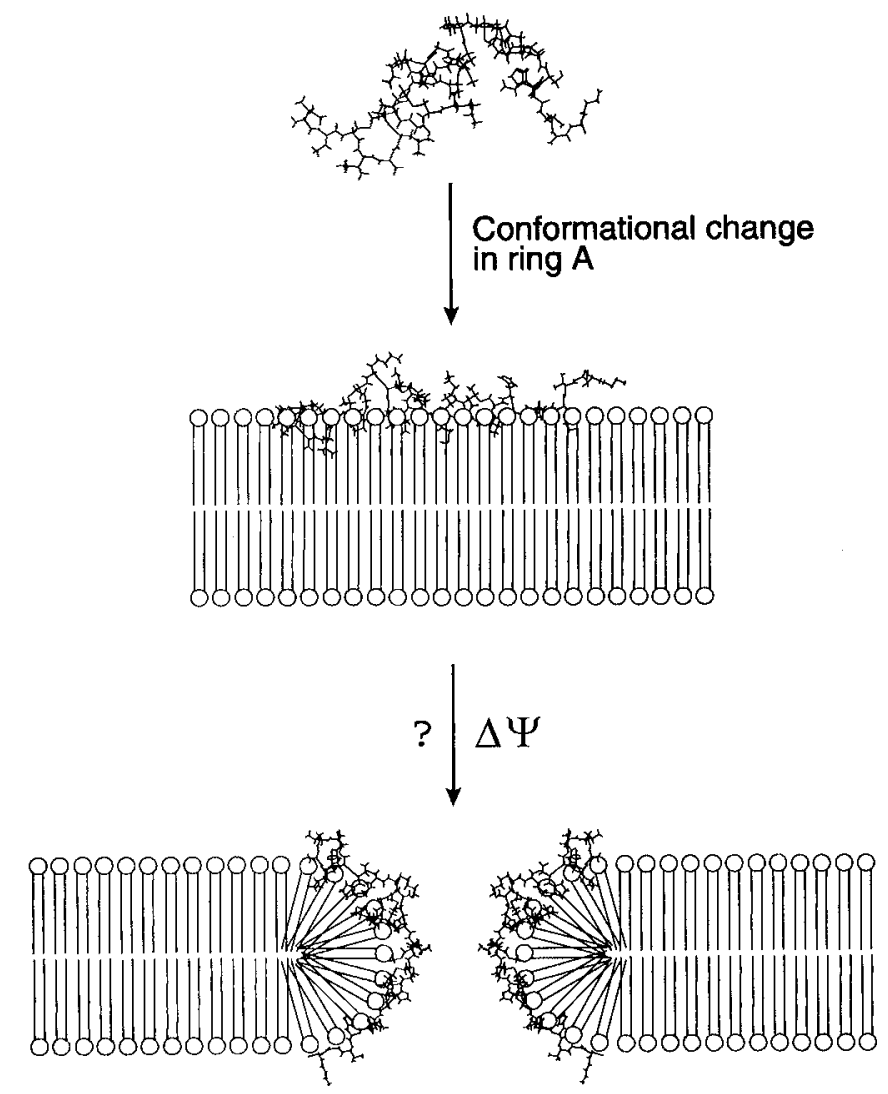

Fig. 8. Model for the pore formation by nisin. See also Driessen et al. (1995). A representative structure of nisin in aqueous solution (van de Ven et al., 1991) is shown at the top, in the middle and in the bottom figure representative structures determined for nisin/DodPCho (van den Hooven et al., 1995) are presented. The first step is the binding of nisin to the membrane. During this process the conformation of ring $\mathrm{A}$, around Dha5, is changed (van den Hooven et al., 1995). The hydrophobic sides of the two structured domains, which are in contact with the micellar model systems, are assumed to be in contact with the planar membrane. Driven by a trans-negative membrane potential, nisin is forced into a state that renders the membrane leaky. Nisin is assumed to be pulled into the membrane as depicted at the bottom of the figure. The structure of nisin changes only in the putative flexible hinge region. The orientation relative to the lipid head-groups is unchanged. The positively charged $\mathrm{C}$-terminus of nisin is, together with attached lipids, drawn across the membrane in response to a trans-negative $A \Psi$.

drophobic residues of the structured domain are immersed in the micelles, whereas the polar and charged residues reside at the charged surface. For this part of the nisin molecule both hydrophobic and electrostatic interactions are likely to be involved in the nisin-micelle contacts. The interactions with the micelles are strongest for the C-terminal residues Ser29-Lys34 as determined from the spin-label experiments as the strongest spin-label-induced line-broadening effects. This is corroborated by the temperature coefficients, which suggested that the amide protons of the residues Ile $30-$ Lys 34 are shielded from the solvent by the micelles (see above).

The antimicrobial activity of nisin has been found to be influenced by the phospholipid composition (Gao et al., 1991; García Garcerá et al., 1993; Driessen et al., 1995). Different activities were observed for liposomes composed of phosphatidylcholine (PtdCho) or phosphatidylglycerol (PtdGro; Driessen et al., 1995). It has been suggested that nisin induces the release of non-bulky anionic fluorescent indicators from phosphatidylcholine liposomes possibly as an anion carrier, an activity 


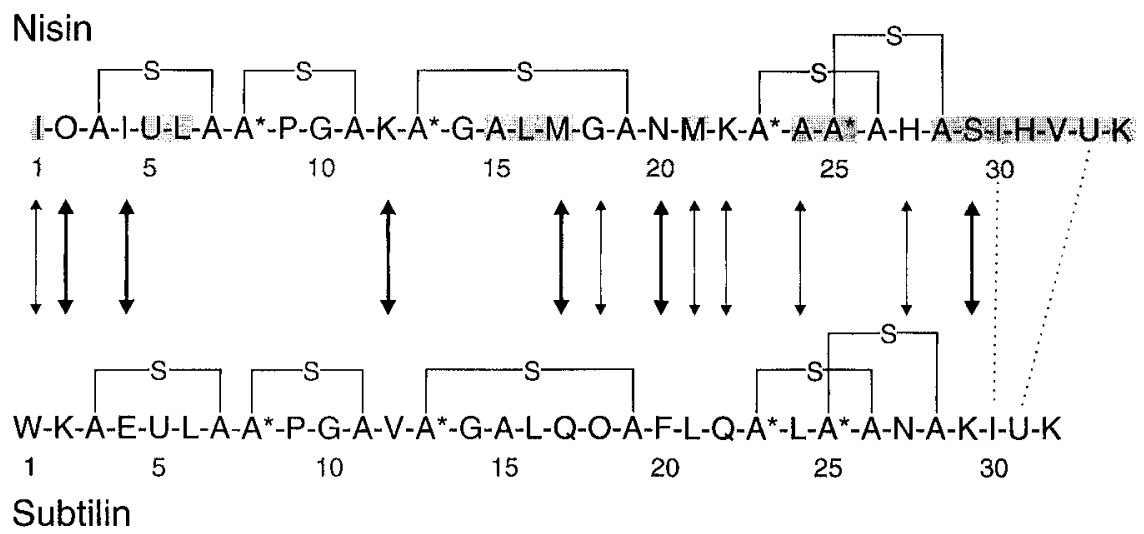

Fig. 9. Comparison of the primary structures of the lantibiotics nisin and subtilin. See the legend of Figure 1 for the one-letter code of the unusual amino acids. Dotted lines mark the region of nisin where a two-residue deletion is found in subtilin. Substitutions of hydrophobic by hydrophilic residues or vice versa are indicated by thick double-headed arrows, substitutions of hydrophobic by hydrophobic residues or of hydrophilic by hydrophilic residues are indicated by thin double-headed arrows. The residues of nisin, which are immersed in the micelles as determined via the spin-label approach, are indicated in grey boxes. Note that the hydrophobic-to-hydrophilic substitutions occur for the residues which are not immersed in the micelles. An apparent exception seems to be Met17, but the side chain of this residue points in the direction of the residue Ala* 13 (van den Hooven et al., 1995), which is just outside the micelle. The conspicuous substitutions are observed for water-exposed residues in nisin and arc thus compatible with our model (see text).

which can be enhanced by a trans-negative membrane potential $(A \Psi)$. This activity is not observed for PtdGro liposomes. Nisin associates with the anionic surface of PtdGro liposomes, and disturbs the lipid dynamics near the phospholipid polar headgroup-water interface in the absence of a $\Delta \Psi$. This process is not directly responsible for pore formation since there is no general loss of the permeability barrier or integrity of the membrane. Nisin requires a threshold $\Delta \Psi$ for pore formation in PtdGro liposomes. The activity of nisin with PtdGro liposomes has been proposed to resemble the in vivo activity more closely than that of nisin with PtdCho liposomes (Driessen et al., 1995). In contrast, the conformation (van den Hooven et al., 1995), location and orientation of nisin relative to the micelles are similar for both zwitterionic and anionic detergents, suggesting that binding to bilayers composed of different lipids will not affect the 3D structure of nisin nor its orientation relative to the membrane. A tighter interaction between nisin and anionic lipids than between nisin and zwitterionic lipids may be the explanation. It has been suggested that nisin interacts in a different manner with PtdCho and PtdGro liposomes (Driessen et al., 1995). Evidence for a tight interaction between nisin and PtdGro liposomes has been obtained (Driessen et al., 1995).

To be able to form pores the cationic nisin requires a transnegative membrane potential (Sahl et al., 1987; Driessen et al., 1995), which forces the molecule into a state that renders the membrane leaky. Evidence was obtained that nisin can traverse the membrane of liposomes composed of zwitterionic PtdCho (Driessen et al., 1995). It is conceivable that anionic phospholipid head-groups interact with the surface-bound cationic nisin and prevent a deep penetration of nisin in the membrane in absence of a $\Delta \Psi$. It is tempting to speculate that a trans-negative membrane potential above a certain threshold pulls the nisin molecule with surrounding anionic lipids in a trans-membrane orientation (Fig. 8 and Driessen et al., 1995) with the hydrophilic side of nisin and the attached lipid head-groups facing the center of the water-filled pore and the hydrophobic surface of nisin and the fatty acid chains of the lipids pointing to the lipid bilayer. Both the polar sides of the cationic nisin and the anionic lipids face the lumen of the pore, which explains the observed non-sclective efflux (Ruhr and Sahl, 1985; Kordel and Sahl, 1986; Sahl, 1991). In such a (tentative) pore nisin is located on a highly curved surface, which resembles the micellar situation. It is clear from the present study that nisin can be situated on such a curved surface. Within this model the presence of a flexible hinge region between the two structured domains proposed for nisin in aqueous solution (van de Ven et al., 1991) and complexed to micelles (van den Hooven et al., 1995) can be rationalized, since in the membrane-bound state the nisin molecule is probably elongated, whereas it has to be more bent in the inserted state. During the proposed insertion process the orientation towards the lipids does not change, whereas in other models (Sahl, 1991; García Garcerá et al., 1993) the interactions between cationic nisin and the lipid head-groups have to be broken to let the nisin molecule slide into the hydrophobic core of the membrane.

Related lantibiotics and nisin mutants. A comparison with related polypeptide sequences has been performed in order to investigate whether the effects that amino acid substitutions have on the bactericidal activity are compatible with our model. So far up to about 25 lantibiotics, subdivided in types A and B, are known (Jung, 1991; Bierbaum and Sahl, 1993; Sahl et al., 1995). Lantibiotics of the first type, including nisin, act primarily by membrane perturbation, while those of the other type appear to inhibit enzyme function. The type-A lantibiotics nisin, subtilin, epidermin and gallidermin are considered because they act according to a similar mechanism and because of the structural homology.

The type-A lantibiotic subtilin (Gross et al,, 1973) bears a strong similarity to nisin: the sequence identity between the two proteins amounts to $60 \%$, the number of lanthionine rings is the same and they are at identical positions in the proteins (Fig. 9). The structure of subtilin in aqueous solution has been determined using NMR spectroscopy and has been suggested to be similar to that of nisin (Chan et al., 1992). In view of the results obtained above for the location and orientation of nisin with respect to the micelles it is interesting to consider possible differences in hydropathy (Kyte and Doolittle, 1982) for the substituted residues. Large changes occur for the residues at positions $2,4,12,17,20$ and 29 , indicated by the thick double-headed arrows in Fig. 9. Apart from residue 17 and 29, these residues are, as evidenced by the spin-label approach, not in contact with 
the micelles but are exposed to water. Resonances of Met17 were influenced by the spin-labels. However, for nisin/Dod $P$ Cho the side chain of Met17 is pointing in the direction of the residue Ala*13, which has an outward orientation. Since the lengths of the side chains of Met and Gln are the same it is likely that the hydrophilic group of GIn in subtilin resides at the surface. Residues His 31 and Val32 in nisin have no equivalent in subtilin and we assume that the presence of a lysine residue at position 29 in subtilin compensates for the loss of the charged His31. Conservative substitutions of hydrophobic by hydrophobic residues or of hydrophilic by hydrophilic residues are indicated by thin double-headed arrows in Fig. 9 and are thought to have no major effect on the process of membrane interaction. Thus, the differences are such that the membrane interaction surface as found for nisin is conserved for subtilin.

The contribution of individual amino acids to the biological activity can be studied with the aid of nisin mutants. A natural nisin variant with an Asn at position 27 instead of a His (Mulders et al., 1991) and two nisin double mutants Met17Gln/Gly18Dhb and Met17Gln/Gly18Thr (Kuipers et al., 1992) have almost the same activity as wild-type nisin (De Vos et al., 1993; Kuipers et al., 1992). This is in line with the preceding discussion, the involved residues are not expected to interact with the micelles except for residue Met17 (but see discussion above and the legend to Fig. 9). In this respect it is also noted that mutagenesis of Dha5 to Ala in subtilin had no effect on the ability to inhibit and lyse vegetative cells, though an intact Dha5 residue appeared critical for spore-outgrowth inhibition, which apparently occurs by a different mechanism (Liu and Hansen, 1993).

Degradation of nisin at Dha5 can result in an opening of the first ring leaving the hydrophobic residues 4 and 6 much more polar (Chan et al., 1989a; Rollema et al., 1991). The observed drop in activity may be ascribed to hampered membrane interactions.

The first 11 residues of the type-A lantibiotics gallidermin and epidermin, including the rings $A$ and $B$, resemble those in nisin and subtilin. The sequence for the first 11 residues of gallidermin is

\section{Ile1-Ala2-Ala3-Lys4-Phe5-Leu6-Ala7-Ala*8-Pro9-Gly10-Ala11;}

the sequence of epidermin is identical to gallidermin with the exception of an Ile at position 6. Compared to nisin, in this part of the sequence of gallidermin three residues are different: Dhb2 versus Ala, Ile4 versus Lys and Dha5 versus Phe (the first mentioned residues are in nisin). An extra difference is encountered between nisin and epidermin, namely a Leu or an Ile at position 6. Only the lysine residue at position 4 causes a dramatic change in hydropathy. However, in nisin this residue was shown not to be in contact with the micelles. It is therefore very likely that this marked difference does not influence the binding of the lantibiotic to the membrane; as far as the first 11 residues are concerned the membrane interaction surfaces of gallidermin and epidermin are thus highly similar to that of nisin.

Conclusions. In combination with our work on the conformation of nisin in aqueous solution (van de Ven et al., 1991) and when complexed to micelles (van den Hooven et al., 1995) the binding to micelles can be described in detail. The micellar systems are considered to model the first step in the mechanism of action of nisin, this step is the binding of nisin to the cytoplasmic membrane of target bacteria. Detailed information on this initial binding step is obtained and an extension of the model for pore formation (Driessen et al., 1995) is proposed. In aqueous solution, the nisin molecule is amphipathic and consists of two structured domains of the residues Alas $3-{ }_{\text {s }}$ Ala19 and Lys $22-{ }_{\text {s }} \mathrm{Ala} 28$, con- nected via a peptide segment which shows structural variability that is most likely caused by flexibility. The molecule binds parallel to the membrane surface, where its amphipathicity is retained. Upon binding, the conformation is changed significantly in the first ring around the important residue Dha5, where two (trans) peptide bonds flip. Structural variability is observed for the region connecting the two structured domains. The molecule is partially immersed, with its hydrophobic residues in the bilayer, whereas the hydrophilic residues are at the surface or just outside the membrane in contact with lipid head-groups.

The authors thank Dr Harry Rollema, NIZO (Dutch Institute for Dairy Research) for expert help with the HPLC purification of nisin, Adri Klaassen for assistance in the ESR experiments, Chantal Doeland for help with the difference spectra and Dr John van Duynhoven for stimulating discussions. All NMR experiments have been performed at the SON National hf NMR facility, Nijmegen. Financial support was obtained from the Netherlands Foundation for Chemical Research (SON) with financial aid from the Netherlands Technology Foundation (STW). MvdK is supported by the EC-BRIDGE program (contract BIOTCT91-0265).

\section{REFERENCES}

Abee, T., Rombouts, F. M., Hugenholtz, J., Guihard, G. \& Letellier, L. (1994) Mode of action of nisin $\mathrm{Z}$ against Listeria monocytogenes Scott A grown at high and low temperatures, Appl. Environ. Microbiol. 60, 1962-1968.

Bax, A. \& Davis, D. G. (1985) MLEV-17-based two-dimensional homonuclear magnetization transfer spectroscopy, J. Magn. Reson. 65, $355-360$.

Bierbaum, G. \& Sahl, H.-G. (1993) Lantibiotics - unusually modified bacteriocin-like peptides from gram-positive bacteria, Zentralbl. Bakteriol. 278, 1-22.

Birdsall, N. J. M., Feeney, J., Lee, A. G., Levine, Y. K. \& Metcalfe, J. C. (1972) Dipalmitoyl-lecithin: assignment of the ${ }^{1} \mathrm{H}$ and ${ }^{13} \mathrm{C}$ nuclear magnetic resonance spectra, and conformational studies, J. Chem. Soc. Perkin Trans. II, 1441-1445.

Bodenhausen, G., Kogler, H. \& Ernst, R. R. (1984) Selection of coherence-transfer pathways in NMR pulse experiments, J. Magn. Reson. $58,370-388$.

Brown, L. R., Bösch, C. \& Wüthrich, K. (1981) Location and orientation relative to the micelle surface for glucagon in mixed micelles with dodecylphosphocholine. EPR and NMR studies, Biochim. Biophys. Acta 642, 296-312.

Brown, L. R., Braun, W., Kumar, A. \& Wüthrich, K. (1982) High resolution nuclear magnetic resonance studies of the conformation and orientation of melittin bound to a lipid-water interface, Biophys. J. 37, 319-328.

Bruno, M. E. C., Kaiser, A. \& Montville, T. J. (1992) Depletion of proton motive force by nisin in Listeria monocytogenes cells, Appl. Environ. Microbiol. 58, 2255-2259.

Chan, W. C., Bycroft, B. W., Lian, L.-Y. \& Roberts, G. C. K. (1989a) Isolation and characterisation of two degradation products derived from the peptide antibiotic nisin, FEBS Lett. 252, 29-36.

Chan, W. C., Lian, L.-Y., Bycroft, B. W. \& Roberts, G. C. K. (1989b) Confirmation of the structure of nisin by complete ' $\mathrm{H}$ NMR resonance assignment in aqueous and dimethyl sulphoxide solution, $J$. Chem. Soc. Perkin Trans. I, 2359-2367.

Chan, W. C., Bycroft, B. W., Leyland, M. L.., Lian, L.-Y., Yang, J. C. \& Roberts, G. C. K. (1992) Sequence-specific resonance assignment and conformational analysis of subtilin by 2D NMR, FEBS Lett. 300, $56-62$

De Vos, W. M., Mulders, J. W. M., Siezen, R. J., Hugenholtz, J. \& Kuipers, O. P. (1993) Properties of nisin $Z$ and distribution of its gene, nisZ, in Lactococcus lactis, Appl. Environ. Microbiot. 59, $213-218$.

Delves-Broughton, J. (1990) Nisin and its application as a food preservative, J. Soc. Dairy Technol. 43, 73-76.

Driessen, A. J. M, van den Hooven, H. W., Kuiper, W., van de Kamp, M., Sahl, H.-G., Konings, R. N. H. \& Konings, W. N. (1995) Mecha- 
nistic studies of lantibiotic-induced permeabilization of phospholipid vesicles, Biochemistry 34, 1606-1614.

Gao, F. H., Abee, T. \& Konings, W. N. (1991) Mechanism of action of the peptide antibiotic nisin in liposomes and cytochrome $c$ oxidasecontaining proteoliposomes, Appl. Environ. Microbiol. 57, 21642170 .

García Garcerá, M. J., Elferink, M. G. L., Driessen, A. J. M. \& Konings, W. N. (1993) In vitro pore-forming activity of the lantibiotic nisin. Role of protonmotive force and lipid composition, Eur. J. Biochem. $212,417-422$.

Godici, P. E. \& Landsberger, F. R. (1974) The dynamic structure of lipid membranes. A ${ }^{13} \mathrm{C}$ nuclear magnetic resonance study using spin labels, Biochemistry 13,362-368.

Griesinger, C., Otting, G., Wüthrich, K. \& Ernst, R. R. (1988) Clean TOCSY for 'H spin system identification in macromolecules, J. Am. Chem. Soc. 110, 7870-7872.

Gross, E. \& Morell, J. L. (1971) The structure of nisin, J. Am. Chem. Soc. 93, 4634-4635.

Gross, E., Kiltz, H. H. \& Nebelin, E. (1973) Subtilin, VI. Die Struktur des Subtilins, Hoppe-Seyler's Z. Physiol. Chem. 354, 810-812.

Henning, S., Metz, R. \& Hammes, W. P. (1986) Studies on the mode of action of nisin, Int. J. Food Microbiol. 3, 121-134.

Hurst, A. (1981) Nisin, Adv. Appl. Microbiol. 27, 85-123.

Ingram, L. (1970) A ribosomal mechanism for synthesis of peptides related to nisin, Biochim. Biophys. Acta 224, 263-265.

Jeener, J., Meier, B. H., Bachmann, P. \& Ernst, R. R. (1979) Investigation of exchange processes by two-dimensional NMR spectroscopy, J. Chem. Phys. 71, 4546-4553.

Jung, G. (1991) Lantibiotica - ribosomal synthetisierte Polypeptidwirkstoffe mit Sulfidbrücken und $\alpha, \beta$-Didehydroaminosäuren, Angew. Chem. 103, 1067-1084.

Kordel, M. \& Sahl, H.-G. (1986) Susceptibility of bacterial, eukaryotic and artificial membranes to the disruptive action of the cationic peptides Pep 5 and nisin, FEMS Microbiol. Lett. 34, 139-144.

Kragh-Hansen, U. \& Riisom, T. (1976) Complexes of aliphatic sulfates and human serum albumin studied by ${ }^{13} \mathrm{C}$ nuclear magnetic resonance spectroscopy, Eur. J. Biochem. 70, 15-23.

Kraulis, P. J. (1991) MOLSCRIPT: a program to produce both detailed and schematic plots of protein structures, J. Appl. Crystallogr. 24, 946-950.

Kuipers, O. P., Rollema, H. S., Yap, W. M. G. J., Boot, H., Siezen, R. J. \& De Vos, W. M. (1992) Engineering dehydrated amino acid residues in the antimicrobial peptide nisin, J. Biol. Chem. 267, 2434024346.

Kyte, J. \& Doolittle, R. F. (1982) A simple method for displaying the hydropathic character of a protein, J. Mol. Biol. 157, 105-132.

Lian, L.-Y., Chan, W. C., Morley, S. D., Roberts, G. C. K., Bycroft, B. W. \& Jackson, D. (1992) Solution structures of nisin A and its two major degradation products determined by n.m.r., Biochem. J. 283 , $413-420$.

Liu, W. \& Hansen, J. N. (1993) The antimicrobial effect of a structural variant of subtilin against outgrowing Bacillus cereus $\mathrm{T}$ spores and vegetative cells occurs by different mechanisms, Appl. Environ. Microbiol. 59, 648-651.

Marion, D. \& Wüthrich, K. (1983) Application of phase sensitive twodimensional correlated spectroscopy (COSY) for measurements of ${ }^{\prime} \mathrm{H}-{ }^{-} \mathrm{H}$ spin-spin coupling constants in proteins, Biochem. Biophys. Res. Commun. 113, 967-974.

Mendz, G. L., Moore, W. J., Brown, L. R. \& Martenson, R. E. (1984) Interaction of myelin basic protein with micelles of dodecylphosphocholine, Biochemistry 23, 6041-6046.

Mendz, G. L., Moore, W. J., Kaplin, I. J., Cornell, B. A., Separovic, F., Miller, D. J. \& Brown, L. R. (1988) Characterization of dodecylphosphocholine/myelin basic protein complexes, Biochemistry $27,379-$ 386.

Mendz, G. L., Brown, L. R. \& Martenson, R. E. (1990) Interactions of myelin basic protein with mixed dodecylphosphocholine/palmitoyllysophosphatidic acid micelles, Biochemstry 29, 2304-2311.

Mendz, G. L., Miller, D. J., Jamie, I. M., White, J. W., Brown, L. R., Ralston, G. B. \& Kaplin, I. J. (1991) Physicochemical characteriza- tion of dodecylphosphocholine/palmitoyllysophosphatidic acid/myelin basic protein complexes, Biochemistry 30,6509-6516.

Menger, F. M. \& Doll, D. W. (1984) On the structure of micelles, J. Am. Chem. Soc. 106, 1109-1113.

Mulders, J. W. M., Boerrigter, I. J., Rollema, H. S., Siezen, R. J. \& De Vos, W. M. (1991) Identification and characterization of the lantibiotic nisin Z, a natural nisin variant, Eur. J. Biochem. 201, 581584.

Okereke, A. \& Montville, T. J. (1992) Nisin dissipates the proton motive force of the obligate anaerobe Clostridium sporogenes PA 3679 , Appl. Environ. Microbiol. 58, 2463-2467.

Papavoine, C. H. M., Konings, R. N. H., Hilbers, C. W. \& van de Ven, F. J. M. (1994) Location of M13 coat protein in sodium dodecyl sulfate micelles as determined by NMR, Biochemistry 33, 1299012997.

Redfield, A. G. \& Kunz, S. D. (1975) Quadrature Fourier NMR detection: simple multiplex for dual detection and discussion, J. Magn. Reson. 19, 250-254.

Rollema, H. S., Both, P. \& Siezen, R. J. (1991) NMR and activity studies of nisin degradation products, in Nisin and novel lantibiotics (Jung, G. \& Sahl, H.-G., eds) pp. 123-130, ESCOM, Leiden.

Ruhr, E. \& Sahl, H.-G. (1985) Mode of action of the peptide antibiotic nisin and influence on the membrane potential of whole cells and on cytoplasmic and artificial membrane vesicles, Antimicrob. Agents Chemother: 27, 841-845.

Sachs, D. H., Schechter, A. N. \& Cohen, J. S. (1971) Nuclear magnetic resonance titration curves of histidine ring protons, J. Biol. Chem. 246, 6576-6580.

Sahl, H.-G., Kordel, M. \& Benz, R. (1987) Voltage-dependent depolarization of bacterial membranes and artificial lipid bilayers by the peptide antibiotic nisin, Arch. Microbiol. 149, 120-124.

Sahl, H.-G. (1991) Pore formation in bacterial membranes by cationic lantibiotics, in Nisin and novel lantibiotics (Jung, G. \& Sahl, H.-G., eds) pp. 347-358, ESCOM, Leiden.

Sahl, H.-G., Jack, R. W. \& Bierbaum, G. (1995) Biosynthesis and biological activities of lantibiotics with unique post-translational modifications, Eur. J. Biochem. 230, 827-853.

Schnell, N., Entian, K.-D., Schneider, U., Götz, F., Zähner, H., Kellner, R. \& Jung, G. (1988) Prepeptide sequence of epidermin, a ribosomally synthesized antibiotic with four sulphide-rings, Nature 333, $276-278$

Slijper, M., Hilbers, C. W., Konings, R. N. H. \& van de Ven, F. J. M. (1989) NMR studies of lantibiotics. Assignment of the ${ }^{1} \mathrm{H}-\mathrm{NMR}$ spectrum of nisin and identification of interresidual contacts, FEBS Lett. 252, 22-28.

Vandenbergh, P. A. (1993) Lactic acid bacteria, their metabolic products and interference with microbial growth, FEMS Microbiol. Rev. 12, $221-238$.

van den Hooven, H. W., Fogolari, F., Rollema, H. S., Konings, R. N. H., Hilbers, C. W. \& van de Ven, F. J. M. (1993) NMR and circular dichroism studies of the lantibiotic nisin in non-aqueous environments, FEBS. Lett. 319, 189-194.

van den Hooven, H. W., Doeland, C. C. M., van de Kamp, M., Konings, R. N. H., Hilbers, C. W. \& van de Ven, F. J. M. (1995) Threedimensional structure of the lantibiotic nisin in the presence of membrane-mimetic micelles of dodecylphosphocholine and of sodium dodecylsulphate, Eur. J. Biochem. 235, 382-393.

van de Ven, F. J. M., van den Hooven, H. W., Konings, R. N. H. \& Hilbers, C. W. (1991) NMR studies of lantibiotics. The structure of nisin in aqueous solution, Eur. J. Biochem. 202, 1181-1188.

van de Ven, F. J. M., van Os, J. W. M., Aelen, J. M. A., Wymenga, S. S., Remerowski, M. L., Konings, R, N. H. \& Hilbers, C. W. (1993) Assignment of ${ }^{1} \mathrm{H},{ }^{15} \mathrm{~N}$, and backbone ${ }^{13} \mathrm{C}$ resonances in detergentsolubilized M13 coat protein via multinuclear multidimensional NMR: a model for the coat protein monomer, Biochemistry 32, $8322-8328$.

Winkowski, K., Bruno, M. E. C. \& Montville, T. J. (1994) Correlation of bioenergetic parameters with cell death in Listeria monocytogenes cells exposed to nisin, Appl. Environ. Microbiol. 60, 4186-4188. 